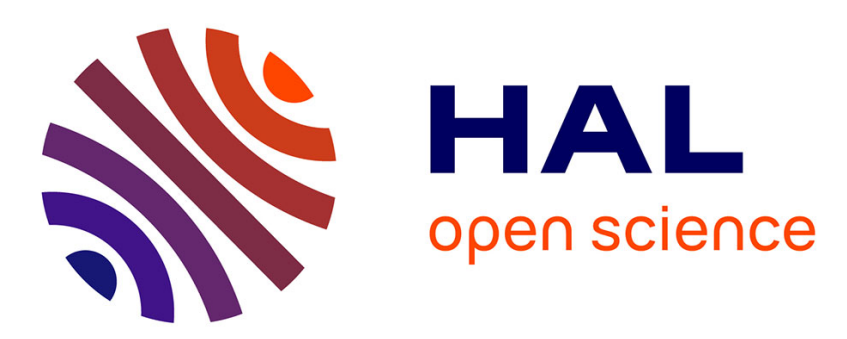

\title{
THE STAND OF THE SYSTEM OF SMECTIC LIQUID CRYSTALS BY MISCIBILITY MEASUREMENTS
}

\author{
H. Sackmann
}

\section{> To cite this version:}

H. Sackmann. THE STAND OF THE SYSTEM OF SMECTIC LIQUID CRYSTALS BY MISCIBILITY MEASUREMENTS. Journal de Physique Colloques, 1979, 40 (C3), pp.C3-5-C3-8. 10.1051/jphyscol:1979302 . jpa-00218692

\section{HAL Id: jpa-00218692 https://hal.science/jpa-00218692}

Submitted on 1 Jan 1979

HAL is a multi-disciplinary open access archive for the deposit and dissemination of scientific research documents, whether they are published or not. The documents may come from teaching and research institutions in France or abroad, or from public or private research centers.
L'archive ouverte pluridisciplinaire HAL, est destinée au dépôt et à la diffusion de documents scientifiques de niveau recherche, publiés ou non, émanant des établissements d'enseignement et de recherche français ou étrangers, des laboratoires publics ou privés. 


\title{
THE STAND OF THE SYSTEM OF SMECTIC LIQUID CRYSTALS BY MISCIBIITY MEASUREMENTS
}

\author{
H. SACKMANN
}

Martin-Luther-Universität Halle-Wittenberg, Sektion Chemie 402 Halle (Saale), Mühlpforte 1, G.D.R.

\begin{abstract}
The systematic investigation of the miscibility between 1.c. phases in binary systems by the Halle Liquid Crystal Group was extended to the following homologous series

\author{
2-[4-n-Alkylphenyl]-5-[4-n-alk oxyphenyl]-pyrimidines, \\ $\mathrm{N}$-[4-n-alkyloxybenzylidene]-4-n-alkyl-anilines, \\ Terephtylidene-bis-[4-n-alkyl-anilines], \\ 4-n-Alkoxyphenyl 4-n-alkylcyclohexanecarboxylates.
}

The different variants of polymorphism in these series including the phase types $\mathrm{N}, \mathrm{A}, \mathrm{C}, \mathrm{F}, \mathrm{B}$ and $\mathrm{G}$ are discussed with respect to structural informations especially on the ordered smectic phases of the types F, B and G. A new phase type $\mathrm{H}$ has to be established. These phases are low temperature modifications in the sequence FGH of the tilted ordered smectic phases.
\end{abstract}

1. Introduction. - The denomination of liquid crystalline (1.c.) phases by letter symbols primarily occurs by miscibility measurements. The existence of complete miscibility between two phases leads to this denomination and this is a thermodynamic criterion. Therefore the phases characterized on this basis by a common symbol belong to one phase type [1].

At the phases of the seven non-nematic phase types named from $A$ to $G$ layer structures have been found, whereas the D phase type possesses a cubic structure [1].

With respect to the characteristics of the structures of the $\mathrm{A}$ and $\mathrm{C}$ phase types there is a principal agreement. The situation is more difficult in the more highly ordered phase types, especially the $B, F$ and $G$ phases $[2,3]$.

In order to get new material the relations of miscibility in and between members of the following four homologous series have been investigated :

$$
\begin{aligned}
& \text { 2-[4-n-alkylphenyl]-5-[4-n-alkoxyphenyl]-pyrimidines (AAOP), } \\
& \text { n-[4-n-alkyloxybenzylidene]-4-n-alkylanilines (ABAA), } \\
& \text { terephtylidene-bis-[4-n-alkylanilines] (TBAA), } \\
& \text { 4-n-alkoxyphenyl 4'-n-alkylcyclohexane-4-carboxylates (AAC) }
\end{aligned}
$$

2. Investigations of the miscibility. - Figure 1 shows the variants of polymorphism found on the investigation of these series [4]. The temperature sequence of all variants can be derived from the following variants

\section{$\mathrm{NACBG}$ \\ NACFG}

by the omission of one or several phases. A change in the sequence has never been observed. Besides phases $\mathrm{N}, \mathrm{A}$ and $\mathrm{C}$, phases of the types $\mathrm{B}, \mathrm{F}$ and $\mathrm{G}$ exist.
In figure 2 all binary combinations are listed which have been investigated in and between the series of the TBAA, AAOP and ABAA [4]. The numbers characterize the members of the series. The lines correlate those two substances the miscibility of which has been investigated in a binary system. At the same time these lines characterize the complete miscibility between the phases of the same letter of the two components. In the systems presented a complete miscibility between phases of the same type has always been found. This is remarkable with respect to the cycles of binary systems which are to 


\begin{tabular}{|c|c|}
\hline $\begin{array}{c}\mathrm{C}_{n} \mathrm{H}_{2 n+1}-\left(\mathrm{O}-\left(\mathrm{N}_{\mathrm{N}}^{\mathrm{N}}\right)-(\mathrm{O})-O \mathrm{C}_{\mathrm{m}} \mathrm{H}_{2 \mathrm{~m}+1}\right. \\
\text { (AAOP) }\end{array}$ & $\begin{array}{l}N A G \\
A C G \\
A C F \\
A C F G\end{array}$ \\
\hline $\mathrm{C}_{\mathrm{n}} \mathrm{H}_{2 \mathrm{n}+1} \mathrm{O}-\mathrm{O}-\mathrm{CH}=\mathrm{N}-\mathrm{O}-\mathrm{c}_{\mathrm{m}} \mathrm{H}_{2 \mathrm{~m}+1}$ & $\begin{array}{l}\text { NG } \\
\text { NAG } \\
\text { NBG } \\
A B G \\
\text { NAB } \\
\text { NAC G } \\
\text { NAC B G }\end{array}$ \\
\hline $\mathrm{C}_{n} \mathrm{H}_{2 n+1}-\left(\mathrm{O}-\mathrm{N}=\mathrm{CH}-\mathrm{O}-\mathrm{CH}=\mathrm{N}-\mathrm{O}-\mathrm{C}_{n} \mathrm{H}_{2 n+1}\right.$ & $\begin{array}{l}\text { NACG } \\
\text { NACFG }\end{array}$ \\
\hline $\mathrm{C}_{n} \mathrm{H}_{2 \mathrm{n}+1}-\mathrm{H}-\mathrm{COO}-\mathrm{O}-\mathrm{OC}_{\mathrm{m}} \mathrm{H}_{2 \mathrm{~m}+1}$ & $\begin{array}{l}\text { NG } \\
\text { NACG } \\
\text { NABG }\end{array}$ \\
\hline
\end{tabular}

FIG. 1. - The variants of polymorphism.

be seen. These cycles support the consistency of the results.

In figure 2 the denomination of the $F$ and $G$ phases occurs by starting the miscibility experiments with

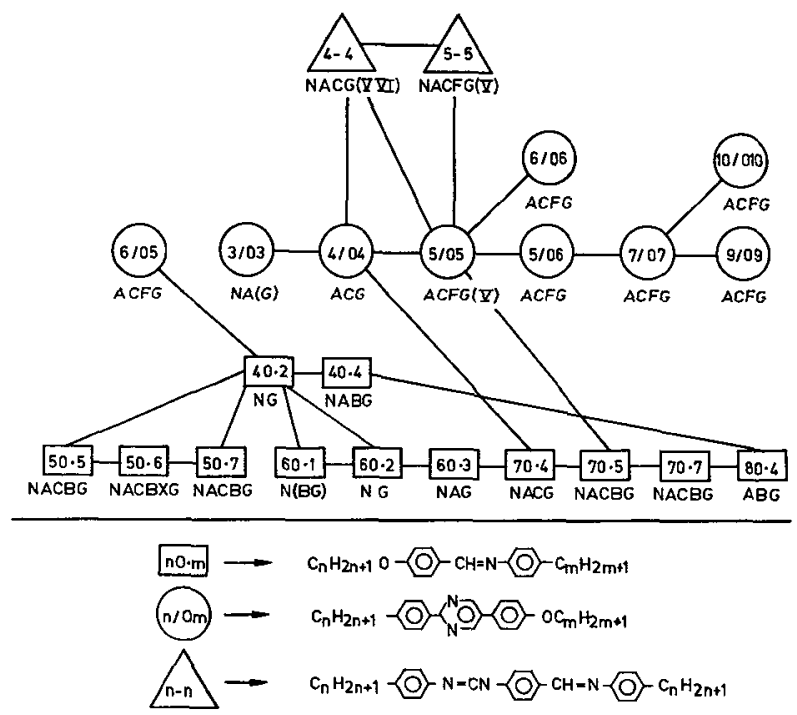

FIG. 2. - The relations of miscibility.

the 5/05 compound of the AAOP series. This standard substance possesses the variant ACFG [5].

Special attention has to be paid to the systems containing the $4-4$ compound of the TBAA series (ТBBA). In the cycle with $5-5$ 4/04, 5/05 compounds all phases named $G$ show complete miscibility in their binary systems.

Also the phases called $V$ in figure 2 show complete miscibility. They are metastable modifications with respect to the crystalline solid. These phases exist as low temperature modifications compared with $F$ and $\mathrm{G}$ phases. The B phases exist as high temperature modifications compared with $G$ phases (see the series of the ABAA in figure 2). As to the structure found in one phase $\mathrm{V}$ there are also differences to the structures of the $E$ phases (see chapter 3). It is therefore very probable that these phases $\mathrm{V}$ represent a new phase type which consequently should be designated by the symbol $\mathrm{H}$.

With respect to the phases of TBBA the results given in figure 2 are in contradiction to former results [2]. As it can be seen in figure 3 the phase of TBBA which now has to be named $G$ has been designated as B phase because there is a complete miscibility with the $B$ phase of the standard substance ethyl 4-[4-ethyloxybenzylidene amino]-cinnamate (EEBC) with the polymorphism NAB.

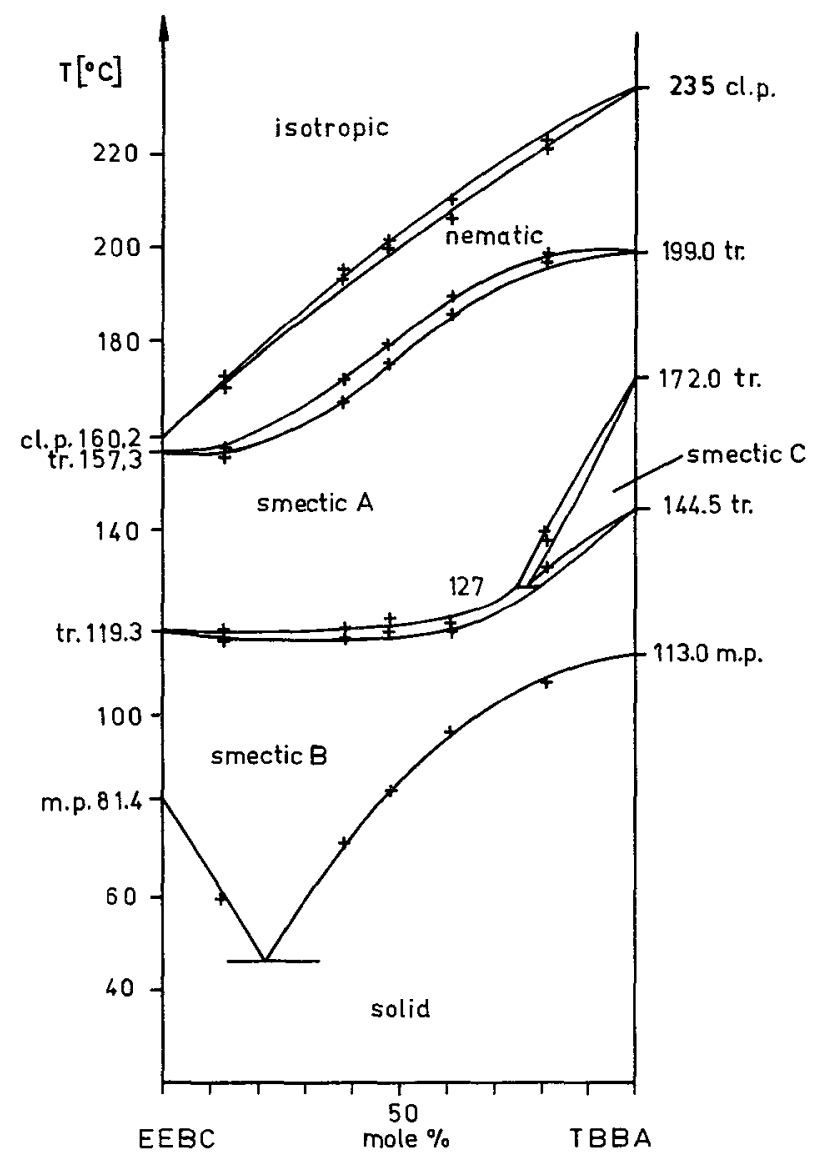

FIG. 3. - The diagram of state of the binary system EEBC-TBBA (former results [2]).

Since Levelut and Lambert [6] have investigated the structures of the B phases of the two compounds the interesting question arose on the miscibility between phases of various structures. The authors have found a layer structure with perpendicularly oriented long molecular axes in EEBC and a tilted layer structure in TBBA.

As a first attempt to answer this question X-ray measurements have been started on the layer distances in the $\mathbf{B}$ mixed phase region shown in figure 3 [7]. Figure 4 shows the layer distances in dependence on 


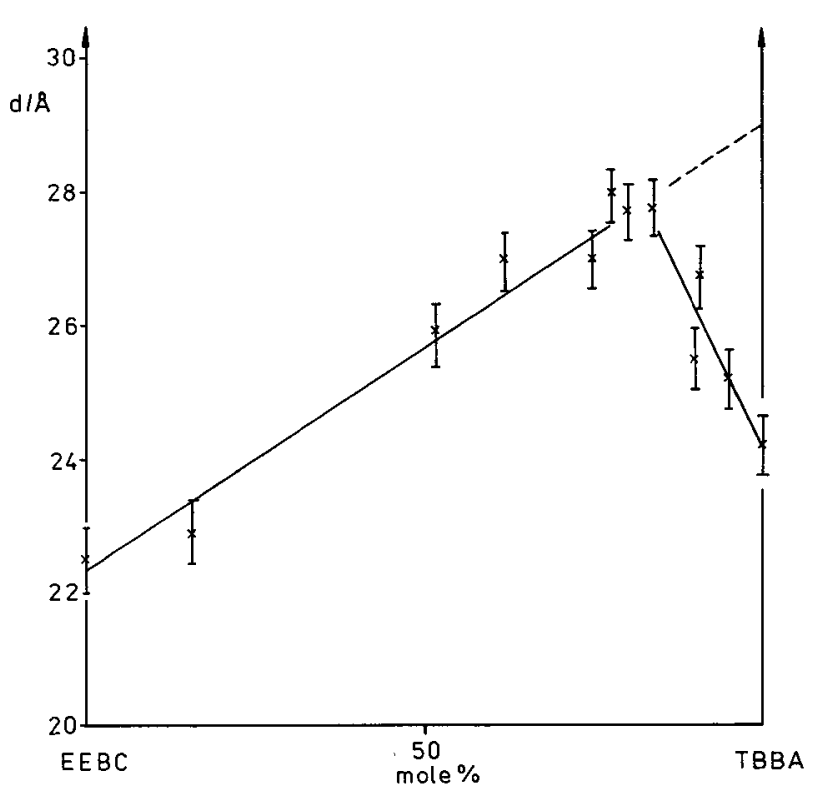

FIG. 4. - Layer distances $d$ in the system of figure 3 or figure 4 respectively [7].

the concentration. Starting from the EEBC a linear increase could be found. In the pure EEBC the layer distance is identical with the length of the stretched molecules. At about 80 molpercent TBBA the values decrease to the layer distance of pure TBBA, indicating a tilted structure. This result indicates a transition from normal structures to tilted ones in the region of 80 molpercent. But the question cannot be clarified if there is a continuous transition or a small two phase region which indicates a gap in miscibility.

This has led to a renewed investigation of the system shown in figure 3 [4]. Small distances in the concentration of the probes were chosen and the concentration field in the contact preparation was searched all over for boundaries between two phases of slightly different textures. These boundaries were found. Their slight shift with the concentration and their vanishing with increasing temperature could be observed. Figure 5 shows the result. There is a two phase region which is small in concentration and decreases strongly with decreasing temperature. Furthermore a very small mixed phase region could be observed, which is probably of an $F$ phase type. This result explains the contradiction to the statement made in figure 3. TBBA has a $G$ phase which is not completely miscible with the $\mathrm{B}$ phase of the EEBC.

3. Phase types and structures. - Today it is possible to classify the layer structures of the thermotropic smectic phases of nonamphiphilic substances. One group summarizes the layer structures that possess a low order of the long molecular axes within the layers. The $\mathrm{A}$ and $\mathrm{C}$ phases belong to this group. The second group summarizes the layer structures that have an ordered arrangement of the long molecular axes in the layers. The B, E, F, G and $\mathrm{H}$ phases belong to this group.

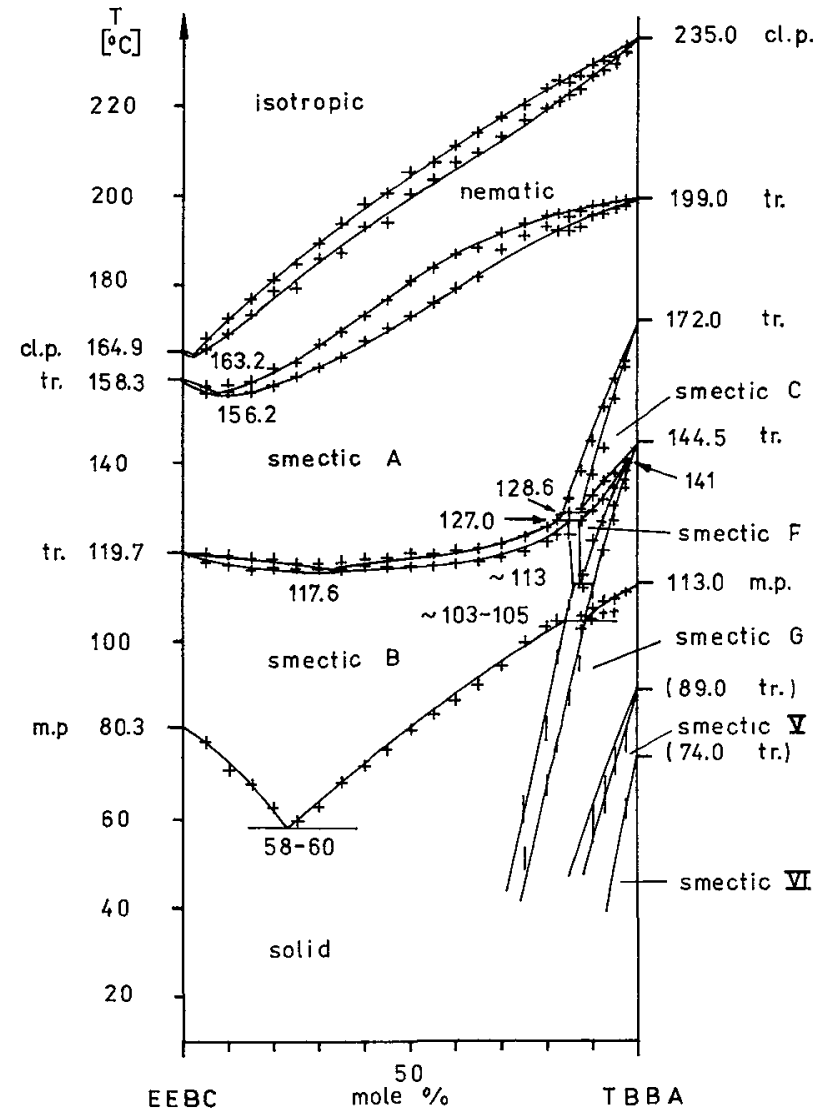

Fig. 5. - The diagram of state of the binary system EEBC-TBBA (new results [4]).

A further subdivision deals with the tilt angle of the long molecular axes to the layer planes. With respect to this orientation of the axes a division into normal (perpendicular oriented molecules) and tilted structures is possible. In A, B and E phases normal structures have been found, whereas tilted structures have been observed in the $\mathrm{C}, \mathrm{F}, \mathrm{G}$ and $\mathrm{H}$ phases.

A further differentiation of the normal and tilted structures of the ordered layer structures concerns the correlation of the rotational order around the long molecular axes. In the normal structures of the phases B (hexagonal structure [6]) there is a higher rotational disorder in comparison to the $\mathrm{E}$ phases (orthorhombic structure of the herring bone type [8, 9]). In the ordered tilted structures there is a higher rotational disorder in the structures of the $G$ phases and probably also of the $F$ phases in comparison to the structures of the $\mathrm{H}$ phases. As to the substances given in figure 2 this general picture can be derived from the $X$-ray measurements on the $B$ and $G$ phases of the homologous series of the ABAA $[3,10,11]\left({ }^{1}\right)$.

(1) In [11] the smectic phase of the 40.2 compound was designated as an $\mathrm{H}$ phase. This is no symbol which is justified by the denomination of 1.c. phases by miscibility measurements. It is a phase of the $G$ type. Therefore there is no connection with the phases $\mathbf{H}$ in this article. 
The investigation of the $\mathrm{G}$ and $\mathrm{H}$ (phase $\mathrm{V}$ in figure 2) phases of TBBA was described in detail [12]. The interpretation of $F$ phase structures as ordered tilted layer structures in the series of the AAOP resulted from X-ray measurements in [13]. The indexing of the X-ray patterns of the $G$ phases in this series was also described in [13] according to the $G$ phase of TBBA.

4. Conclusion. - The results communicated in chapter 2 arrange the phases of four homologous series in the thermodynamic system of phase types. Because of the high degree of polymorphism in some members of the series there is a special interest in the questions concerning the system of liquid crystal- line polymorphism. As can be seen in the figures 1 and 2 the phases belong to the already described phases of the types N, A, C, B, F and G. Only the member 50.6 possesses a phase $(\mathrm{X})$, which has not been classified so far.

Additionally the results led to a refined investigation of the binary system of TBBA and EEBC (Fig. 5). $A$ gap of miscibility between the $G$ and $B$ phases has been found in accordance with the results given in figure 2 . This refinement and the miscibility between the phases $\mathrm{V}$ given in figure 3 make its denomination as a phase type $\mathrm{H}$ possible.

A comparison with available data (chapter 3) shows that all phases of one type have the same or very similar structures which are distinguished from the structures of the phases of an other phase type.

\section{References}

[1] Sackmann, H., Demus, D., Mol. Cryst. Liq. Cryst. 21 (1973) 239.

[2] Richter, L., Demus, D., Sackmann, H., J. Physique Colloq. 37 (1976) C3-41.

[3] Doucet, J., Levelut, A. M., J. Physique 38 (1977) 1136.

[4] RichTER, L. et al., to be published.

[5] Demus, D., Diele, S., KlapperstüCK, M., Link, V., ZaschKe, H., Mol. Cryst. Liq. Cryst. 15 (1971) 161.

[6] Levelut, A. M., Lambert, M., C. R. Hebd. Séan. Acad. Sci. B 272 (1971) 1018.
[7] Diele, S., Nasta, L., Sackmann, H., Kristall und Technik 12 (1977) 1063.

[8] Diele, S., Phys. Status Solidi (a) 25 (1974) K183.

[9] Doucet, J., Levelut, A. M., Liebert, H., Strzelecki, L., J. Physique Colloq. 36 (1975) Cl-

[10] De Jeu, W. H., Porter, J. A., Phys. Lett. 61 (1977) A 114.

[11] De Vries, A., Fishel, D., Mol. Cryst. Liq. Cryst. 16 (1972) 311.

[12] Doucet, J., Levelut, A. M., Lambert, M., Phys. Rev. Lett. 32 (1974) 301.

[13] Diele, S. et al., Acta Polonica in print. 